\title{
Modeling the Impact of Microgravity at the Cellular Level: Implications for Human Disease
}

\author{
Peta Bradbury ${ }^{1}$, Hanjie Wu ${ }^{2}$, Jung Un Choi ${ }^{3}$, Alan E. Rowan ${ }^{3}$, Hongyu Zhang ${ }^{4}$, \\ Kate Poole ${ }^{5}$, Jan Lauko ${ }^{3}$ and Joshua Chou ${ }^{2 *}$ \\ ${ }^{1}$ Respiratory Technology, Woolcock Institute of Medical Research, Sydney, NSW, Australia, ${ }^{2}$ School of Biomedical \\ Engineering, Faculty of Engineering and Information Technology, University of Technology Sydney, Sydney, NSW, Australia, \\ ${ }^{3}$ Australian Institute for Bioengineering and Nanotechnology, The University of Queensland, Brisbane, QLD, Australia, ${ }^{4}$ State \\ Key Laboratory of Tribology, Department of Mechanical Engineering, Tsinghua University, Beijing, China, ${ }^{5}$ EMBL Australia \\ Node in Single Molecule Science, School of Medical Sciences, University of New South Wales, Sydney, NSW, Australia
}

A lack of gravity experienced during space flight has been shown to have profound effects on human physiology including muscle atrophy, reductions in bone density and immune function, and endocrine disorders. At present, these physiological changes present major obstacles to long-term space missions. What is not clear is which pathophysiological disruptions reflect changes at the cellular level versus changes that occur due to the impact of weightlessness on the entire body. This review focuses on current research investigating the impact of microgravity at the cellular level including cellular morphology, proliferation, and adhesion. As direct research in space is currently cost prohibitive, we describe here the use of microgravity simulators for studies at the cellular level. Such instruments provide valuable tools for cost-effective research to better discern the impact of weightlessness on cellular function. Despite recent advances in understanding the relationship between extracellular forces and cell behavior, very little is understood about cellular biology and mechanotransduction under microgravity conditions. This review will examine recent insights into the impact of simulated microgravity on cell biology and how this technology may provide new insight into advancing our understanding of mechanically driven biology and disease.

Keywords: microgravity, mechanobiology, mechanotransduction, cytoskeletal, mechanosensing

\section{INTRODUCTION}

Humans are subjected to persistent gravitational force and the importance of gravity for maintaining physiological function has been revealed by the detrimental impacts of space travel on human health. During space flight, astronauts are exposed to a prolonged state of microgravity and develop a myriad of physiological disruptions including a loss of muscle mass and bone density, impaired vision, decreased kidney function, diminished neurological responses, and a compromised immune system (White and Averner, 2001; Horneck et al., 2003; Crucian et al., 2014; White et al., 2016). This review will discuss recent data that highlight the impact of microgravity at the cellular level. Additionally, this review addresses how such research can be conducted on earth by simulating the microgravity state. These studies are not only important for understanding how humans are affected by microgravity but have the potential to elucidate the role of mechanical stimuli on cellular function and the development of mechanically driven disease states.

Mechanobiology is the study of how cells are influenced by their physical environment. This emerging field of research provides an important perspective on understanding 
many aspects of cellular function and dysfunction. Cells can convert mechanical inputs into biochemical signals to initiate downstream signaling cascades in process known as mechanotransduction. Gravitational force is presumed to play a crucial role in regulating cell and tissue homeostasis by inducing mechanical stresses experienced at the cellular level. Thus, the concept of mechanical unloading (a decrease in mechanical stress) is associated with the weightlessness of space and can be replicated by simulating microgravity conditions, allowing for investigation of the mechanobiology aspects of cell function. The mechanical unloading of cells under microgravity conditions shifts the balance between physiology and pathophysiology, accelerating the progression and development of some disease states. For example, kidney stone formation is accelerated under microgravity conditions compared to Earth's gravity (1 g) (Pavlakou et al., 2018). Similarly, osteoporosis can take decades to develop under normal gravitational loading, yet this disease can be modeled under microgravity over shorter time scales (Pajevic et al., 2013). The mechanisms by which human physiology are disrupted in microgravity remain unknown, rendering numerous open questions regarding the adaptive changes that occur at the cellular and molecular level in response to microgravity.

\section{SIMULATING MICROGRAVITY}

One of the key challenges in using microgravity as an investigative tool is creating a microgravity condition that can be applied at a cellular level, on Earth. The process of conducting space research missions is costly and time consuming, thereby limiting the advancement of microgravity research and widespread application of this approach. Currently, there are a number of microgravity devices available for purchase that are designed to achieve microgravity conditions. Microgravity simulators specific to cellular studies include strong magnetic field-induced levitation (i.e., diamagnetic simulation), as well as two-dimensional and three-dimensional clinostats, rotating wall vessels and random positioning machines (RPMs) (Huijser, 2000; Russomano et al., 2005; Herranz et al., 2012; Ikeda et al., 2017). Each of the simulation techniques has shown advantages and disadvantages however, when chosen correctly for a given experiment, the results obtained are similar to those observed in Space flight studies (Stamenkovic et al., 2010; Herranz et al., 2013; Martinez et al., 2015; Krüger et al., 2019b). For cell culture studies, the use of RPM is common as the system achieves microgravity by continually providing random changes in orientation relative to the gravity vector and thus an averaging of the impact of the gravity vector to zero occurs over time (Beysens and van Loon, 2015). This averaging is achieved by the independent, yet simultaneous, rotation of two axes - with one axis rotating in the $X$-plane, and the second axis rotating in the $Y$-plane. It is important that the cell culture flask/sample be placed at the midpoint of the $x$-axis, cell culture flasks placed at a distance from the center of the $x$-axis will be subjected to a greater rotational force resulting in cells experiencing both centrifugal force and an increased gravity load (Beysens and van Loon, 2015). Furthermore, the RPM is designed to subject the cells to
$10^{-3} \mathrm{~g}$ (or as close to this value as possible) but cannot achieve complete zero gravity and hence termed microgravity (Huijser, 2000; Beysens and van Loon, 2015).

\section{THE IMPACT OF MICROGRAVITY OF CELL CYTOSKELETON}

Cellular response to mechanical loading has been well documented over the decades however, the response that occurs when cells are placed under conditions of mechanical unloading remains in its infancy. The most apparent cellular changes that occur following exposure to a microgravity environment are alterations to cell shape, size, volume, and adherence properties (Buken et al., 2019; Dietz et al., 2019; Thiel et al., 2019b). These microgravity induced changes to cellular morphology reflect modifications to cytoskeletal structures, namely microtubules and actin filaments (F-actin), as cells sense a reduced gravitational load and therefore mechanical unloading (Crawford-Young, 2006; Corydon et al., 2016a; Thiel et al., 2019a). Microgravity, whether in Space or simulated in the laboratory, offers a unique mechanical unloading environment to explore cellular mechanotransduction by providing an unparalleled research environment to investigate the relationship between mechanical unloading and cellular response.

Numerous studies have been conducted on a myriad of cell types highlighting morphological sensitivity to microgravity (Ingber, 1999; Vorselen et al., 2014), with the first documented morphological change reported by Rijken et al. (1991). Morphological changes as a result of microgravity conditions, either real or simulated, have been shown to have altered transcription, translation, and organization of cytoskeletal proteins (Vassy et al., 2001; Infanger et al., 2006b; Tauber et al., 2017). Fundamental work carried out by Tabony, Pochon, and Papaseit showed that while tubulin self-assembly into microtubules occurs independent of gravity, the assembly and organization of the microtubule network is gravity dependent (Papaseit et al., 2000; Tabony et al., 2002). Importantly, this gravity-dependent organization of the microtubule network has since been described in multiple cell lines during both real and simulated microgravity exposures (Vassy et al., 2001; Uva et al., 2002; Hughes-Fulford, 2003; Rosner et al., 2006; Janmaleki et al., 2016) and possibly be the result of a poorly defined microtubule organizing center (MTOC) (Lewis et al., 1998). Taken together these data highlight an important regulatory role for the microtubule network and the MTOC following exposure to a microgravity environment. However, the data surrounding the response of the actin cytoskeleton to microgravity exposure are less clear. Many studies have reported that microgravity exposure had decreased expression of actin and actin-associated proteins, namely Arp2/3 and RhoA, subsequently resulting in the disorganization of the actin cytoskeleton (Carlsson et al., 2003; Higashibata et al., 2006; Corydon et al., 2016a,b; Louis et al., 2017; Tan et al., 2018). However, other studies have showed increased F-actin and stress fiber formation that accompanied the development of lamellipodia protrusions following exposure to microgravity (Gruener et al., 1994; Nassef et al., 2019). Contrary 
to this, Rosner et al. (2006) reported no changes to actin structure or organization and further suggested that the actin cytoskeleton is only regulated in a hyper-gravity environment. Thus, the data surrounding cellular morphological changes in response to microgravity and the role of actin is confounding and at times contradictory.

The actin cytoskeleton, its organization and ability to generate force are critical for cellular mechanosensing and importantly any changes to these processes can initiate pathophysiological disruption. Transduction of mechanical forces by integrins requires clustering of these transmembrane receptors and the subsequent formation of focal contacts and adhesions that physically link the extracellular matrix (ECM) to the cytoskeleton (Wang et al., 1993; Ingber, 1997; Maniotis et al., 1997). Binding of integrins to matrix proteins promotes the bundling of F-actin at the cell-matrix adhesion and the subsequent maturation of both the focal adhesion and the actin stress fiber (Zaidel-Bar et al., 2003; Wolfenson et al., 2009, 2011) to generate the tension required for cell adherence, migration, and tissue homeostasis. Exposure to microgravity reduces the formation, number, and total area of focal adhesions per cell (Guignandon et al., 2003; Tan et al., 2018) consequently affecting cellular adherence, migration capacity, and viability (Plett et al., 2004; Nabavi et al., 2011; Shi et al., 2015; Ahn et al., 2019; Dietz et al., 2019), albeit with contradictory results. Mechanical unloading has been shown to significantly reduce gene expression of a number of focal adhesion proteins, including FAK, DOCK1, and PTEN, while caveolin and p130Cas expression were shown to be increased (Grenon et al., 2013; Ratushnyy and Buravkova, 2017). Thus, the activity of the downstream signaling pathways that govern the microgravity-induced cytoskeletal changes are significantly impaired and are at least in part due to the microgravitytriggered inhibition of FAK and/or RhoA signaling (Higashibata et al., 2006; Li et al., 2009; Tan et al., 2018). Furthermore, recent data suggest that changes to the cytoskeleton may also impact signaling via mechanically activated ion channels and contacts in response to both cell-generated (Nourse and Pathak, 2017; Ellefsen et al., 2019) and externally applied mechanical inputs (Bavi et al., 2019). Thus, downstream signaling of the numerous mechanotransduction pathways depend on the concerted interaction of the cytoskeleton, cell adhesion molecules, and force sensing proteins, including mechanically activated ion channels. To date, there is little information regarding the role of mechanically activated ion channels in microgravity environments.

\section{MICROGRAVITY IMPACT BONE CELL SIGNALING RESPONSE AND CARTILAGE ECM SYNTHESIS}

The accelerated loss of bone and muscle mass as a result of microgravity has been well documented over the decades (Burger and Klein-Nulend, 1998; Harris et al., 2000; Fitts et al., 2001). Osteocytes and osteoblasts are known mechanosensitive bone cells responsible for maintaining the balance of bone absorption and resorption - a process that is coordinated by both the actin cytoskeleton and microtubule network (Okumura et al., 2006). Bone cell morphology is significantly modified following exposure to microgravity when compared to control cells (Guignandon et al., 1995; Hughes-Fulford, 2003). To adapt to the new mechanical environment the bone cells have reduced transcription and translation of cytoskeletal and cytoskeletalassociated proteins (Xu et al., 2017; Mann et al., 2019), decreased focal adhesion formation, together resulting in the increased formation of osteoclast resorption pits (Nabavi et al., 2011). Furthermore, the actin cytoskeleton of osteoblasts subjected to 4 days of microgravity exposure completely collapsed (HughesFulford, 2003), significantly impacting multiple downstream signaling pathways, most notably, the inhibition of bone morphogenic protein (BMP) signaling axis (Patel et al., 2007; $\mathrm{Xu}$ et al., 2017). The BMP family of proteins regulates the expression of an important mechanosensing protein, sclerostin, found exclusively in osteocytes (Poole et al., 2005; Kamiya et al., 2016), whereby mechanical unloading increases sclerostin protein expression to promote bone resorption and cause a loss of bone density (Robling et al., 2008) - a phenotype that closely mimics both osteoporosis and osteonecrosis. Thus by applying the unique mechanical unloading environment offered by both real and simulated-microgravity to bone (specifically, osteoporosis) research has led to the introduction of the FDA approved drug, Evenity, a monoclonal antibody that works as an anabolic agent to increase bone mass via the sclerostin pathway (Scheiber et al., 2019).

While a significant number of studies have identified the importance of mechanical unloading in regulating bone structure and function, the articular cartilage (AC) is also particularly susceptible to the effects of mechanical loading and unloading (Sanchez-Adams et al., 2014). The cells found in AC, chondrocytes, sense and respond to changing mechanical loads in order to maintain the balanced production of ECM molecules ensuring that the tissue maintains the ability to resist tensile and compressive forces. Both mechanical unloading and overloading of chondrocytes can disrupt the homeostatic balance in the cartilage leading to cartilage degradation and osteoarthritis thereby tipping the balance from homeostatic maintenance to pathophysiology, leading to cartilage degradation and osteoarthritis (Vanwanseele et al., 2002; Kurz et al., 2005). To study the effect of extended microgravity on AC specifically on the joint tissue, mice were exposed to 30 days of spaceflight during the Bion-M1 mission (Fitzgerald et al., 2019). Interestingly, tissue degradation was observed only in the AC of load-bearing joints, but not in minimally loaded sternal fibrocartilage highlighting a differential response to mechanical unloading and the predisposition of load bearing joints, but not structural joints, to mechanical stimuli. Additionally, decreased proteoglycan levels were found in the AC of the mice after the 30 days (Vanwanseele et al., 2002) further characterizing a mechanical unloading pathology specific to AC atrophy. Importantly, reduced proteoglycan levels have also been reported in hindlimb unloading and limb immobilization studies in various animals (Salter et al., 1980; Haapala et al., 1996; O'Connor, 1997). The reduced proteoglycan levels paired with 
Cytoskeleton organization during microgravity exposure

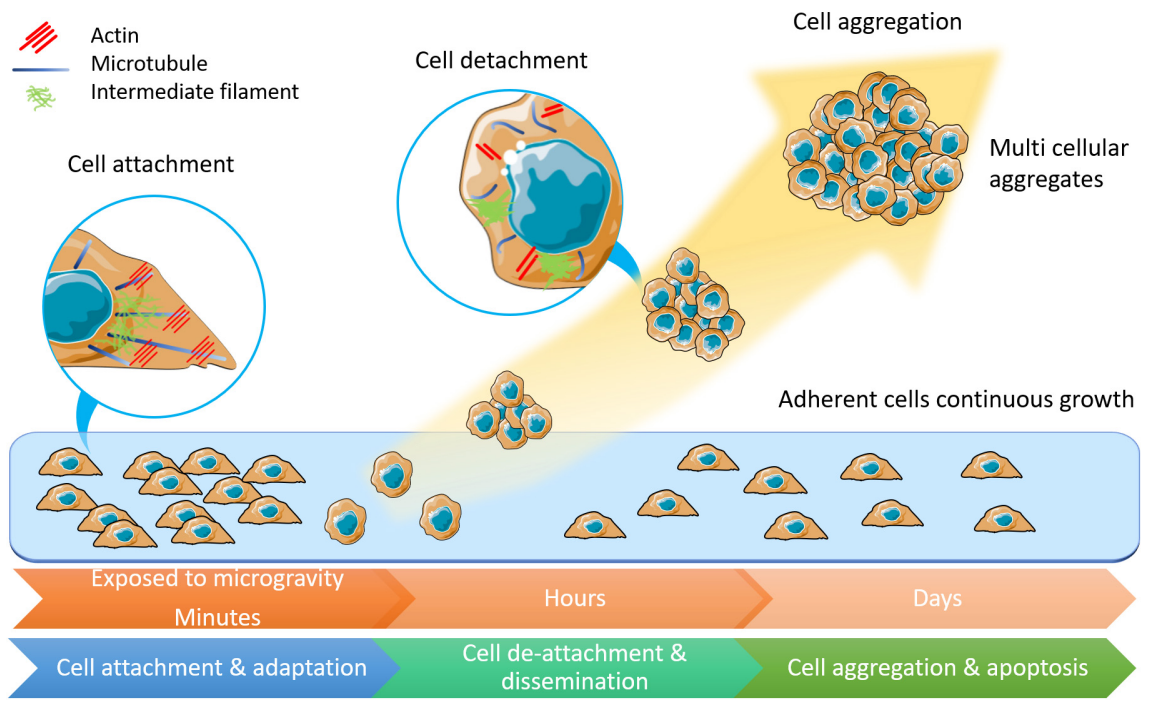

FIGURE 1 | The morphology and physiology alterations of adherently growing cells after microgravity exposure. Cytoskeleton components of actin, microtubules and intermediate filament are displayed in inset circles. In adherent cells, microtubules form radiation arrangement near nuclear. Actin fibers anchor to cell membranes. Intermediate filament forms loose network around nuclear. Among cells under microgravity influence, the microtubules are shortened and curved. Less actin fibers but more condense intermediate filament are observed. This illustration was inspired by long-term thyroid cells culture in simulated microgravity environment (Kopp et al., 2015; Krüger et al., 2019a) .

the augmented regulation of ECM-associated genes and proteins that help protect against osteoarthritic changes, including collagen type I, II, and X, $\beta_{1}$ integrin, vimentin, and chondrocyte sulfate (Ulbrich et al., 2010; Aleshcheva et al., 2013, 2015), suggest that while the microgravity-induced osteoarthritic pathology is observed cartilage recovery of the AC is possible. Further to this, cell-based studies have shown that primary chondrocytes are to adapt to a microgravity environment within $24 \mathrm{~h}$ (Aleshcheva et al., 2013). There is a clear need for more research into the response of $\mathrm{AC}$ and specifically chondrocytes as elucidation of the molecular mechanism that underpins chondrocytes mechanoadaptation to a microgravity environment, holds great promise for novel osteoarthritic treatments.

\section{MICROGRAVITY-INDUCED CYTOSKELETAL REGULATION OF IMMUNE AND CANCER CELLS}

The function of the immune system is strongly impacted (Frippiat et al., 2016; Smith, 2018) with several studies reporting dysregulation or immunosuppression following simulated or real microgravity conditions (Boonyaratanakornkit et al., 2005; Crucian et al., 2015; Martinez et al., 2015; Thiel et al., 2017). Peripheral monocytes collected from astronauts post shortduration Space missions (13-16 days) showed that there was no change in the numbers of circulating monocytes indicating that the change to an immunosuppressive phenotype was not due a reduced cell number (Crucian et al., 2011). However, peripheral monocytes showed a significantly decreased expression of surface markers CD26L and HLA-DR, known regulators of lymphocyteendothelial cell adhesion and tissue migration (Crucian et al., 2011). In vitro studies performed during Space flights have revealed that lymphocytes exhibit important changes in their cytoskeletal properties, suggesting that $\mathrm{T}$ cell activation may be compromised at the level of the $\mathrm{T}$ cell receptor (TCR) interaction (Sonnenfeld et al., 1992). It has been hypothesized that immunosuppression produced in microgravity is due to impaired TCR activation resulting from cytoskeletal disruption (Bradley et al., 2019); however, the underlying molecular mechanisms remain unknown.

When applied to tumor cells microgravity has been found to impact tumor cell adhesion, proliferation, migration, and viability (Grimm et al., 2002; Plett et al., 2004; Infanger et al., 2006a; Shi et al., 2015; Tan et al., 2018), and to induce cell autophagy (Jeong et al., 2018). Changes in apoptotic rate were also observed in colorectal cancer cells (DLD-1) and a lymphoblast leukemic cell line (MOLT-4), accompanied by reduced transcription of the genes involved in colony formation, oncogenic progression, and metastatic potential (Vidyasekar et al., 2015). The foremost changes to tumor cell following exposure to microgravity are alterations of cell shape, size, and adhesion, indicating changes in cytoskeletal organization (Figure 1). Modulation of the cytoskeletal network have been demonstrated to occur after just minutes (Rijken et al., 1992; Sciola et al., 1999) or hours (Lewis et al., 1998; Vassy et al., 2001) in microgravity. Microtubule disorganization was observed in both the breast cancer MCF-7 cells and the thyroid cancer cell line FTC-133 when exposed to real microgravity (Kopp et al., 2018a,b). In contrast, no changes in Rac-controlled F-actin were detected in the neuroblastoma cell line, SH-Y-5Y (Rosner 
TABLE 1 | Effects of sub-cellular functions concerning various cell types and exposure duration in microgravity environment.

\begin{tabular}{|c|c|c|c|}
\hline Cell type & Effects of cells & Microgravity exposure time & References \\
\hline Osteosarcoma cells (ROS 17/2.8) & $\begin{array}{l}\text { Cell morphological change to rounded shape with long } \\
\text { cytoplasmic extensions }\end{array}$ & 4 days and 6 days & Guignandon et al., 1997 \\
\hline Osteosarcoma cells (ROS 17/2.8) & $\begin{array}{l}\text { Reduction in cell spread area and vinculin spot area, actin } \\
\text { and focal adhesion, and stress fibers }\end{array}$ & 12 and $24 \mathrm{~h}$ & Guignandon et al., 2003 \\
\hline Breast cancer (MCF-7) & Disoriented microtubule & $1.5 \mathrm{~h}$ & Vassy et al., 2003 \\
\hline Thyroid cancer (ML-1) & Actin fiber reorganization & Parabola flight & Ulbrich et al., 2011 \\
\hline Human macrophages & No effect on cytoskeletal structure & 11 days & Tauber et al., 2017 \\
\hline Human chondrocytes & $\begin{array}{l}\text { Effect on cell cytoplasm, microtubule network disruption, } \\
\text { loss of stress fibers, actin fiber reorganization. }\end{array}$ & Parabola flight & Aleshcheva et al., 2015 \\
\hline Osteoblasts (MC3T3-E1) & $\begin{array}{l}\text { Reduction in actin cytoskeletal stress fibers and reduction } \\
\text { of nuclei size by } 30 \%\end{array}$ & 4 days & Hughes-Fulford and Lewis, 1996 \\
\hline Primary mouse osteoblasts & $\begin{array}{l}\text { Thicker microtubule, smaller focal adhesion spots, } \\
\text { reduction in actin stress fibers, and increase in cell spread } \\
\text { area }\end{array}$ & 5 days & Nabavi et al., 2011 \\
\hline Osteocytes & $\begin{array}{l}\text { Increase in cellular organelles including Golgi complex, } \\
\text { vacuoles, and vesicles }\end{array}$ & 14 days & Rodionova et al., 2002 \\
\hline
\end{tabular}

et al., 2006), highlighting the differing responses of distinct cell types to mechanical unloading. The expression of focal adhesion proteins, moesin and ezrin, was found to be significantly downregulated after 24-h of microgravity exposure (Kopp et al., 2018a). There remains a gap in the understanding of the molecular mechanisms that drive changes in the cytoskeleton in response to mechanical unloading and the physiological systems that will be impacted by microgravity. Thus, there is a dual potential of microgravity studies in both elucidating the underlying importance of mechanical signaling in human physiology and in developing understanding and countermeasures for longduration space flights.

\section{DISCUSSION}

Microgravity research conducted on the International Space Station (ISS) and in simulated microgravity has highlighted the importance of cellular mechanotransduction in human health and disease (Table 1). Understanding the molecular mechanisms by which cells respond to mechanical unloading will not only be important for preparing humans for longer-term space exploration but may also contribute to therapeutics for the treatment of diseases that depend on mechanical interactions, highlighting opportunities to manipulate and correct certain disease states. The discovery of sclerostin and the subsequent generation and use of the sclerostin monoclonal antibody to treat both osteoporotic patients has been a major outcome of the field (Martin et al., 2020). Thus, Space and microgravity biological research constitute extreme environments in which novel mechanotransduction molecules and mechanosensing mechanisms can be identified and may prove helpful in better designing immunotherapies or developing better and more targeted anti-cancer therapies. Studies that leverage these low gravity environments have the unique potential to unveil important physiological changes that occur in response to changing mechanical loads and are of considerable importance in expanding our understanding of mechanobiology.
With the privatization and commercialization of the ISS and a global push toward the exploration of space, the gateway for conducting research under simulated and Space microgravity is becoming more accessible. In particular the development of different variations of the RPM device provides a simulated microgravity environment on Earth for investigating the changes in cellular function due to mechanical unloading. Over the last several years, experiments involving the use of microgravity to study cellular mechanobiology and disease mechanisms have continued to rise, reinforcing the importance of this platform. This area of research has highlighted the importance of mechanical cues in maintaining cell and tissue homeostasis. The emergence of Space mechanobiology will continue to rise in the foreseeable future as it is evident that the benefits of such research can catapult survival of astronauts in space for extended duration as well as developing understanding and better treatments for Earth-borne diseases.

\section{AUTHOR CONTRIBUTIONS}

PB contributed to the sections "Simulating Microgravity" and "The Impact of Microgravity of Cell Cytoskeleton." $\mathrm{JuC}$ and JL contributed to the section "Microgravity Impact Bone Cell Signaling Response and Cartilage ECM Synthesis." $\mathrm{HW}, \mathrm{HZ}$, and KP contributed to the section "MicrogravityInduced Cytoskeletal Regulation of Immune and Cancer Cells." $\mathrm{AR}, \mathrm{KP}$, and JoC initiated, conceptualized the review, and edited the manuscript.

\section{FUNDING}

The author acknowledges the support of the Australian Research Council Discovery Project (ARC DP) (DP190101973), the NHMRC project grant APP1122104, and the University of Technology Sydney FEIT 2019 BlueSky grants FL160100139 (Laureate Fellowship AER) and DP190102230 (DP AER). 


\section{REFERENCES}

Ahn, C. B., Lee, J. H., Han, D. G., Kang, H. W., Lee, S. H., Lee, J. I., et al. (2019). Simulated microgravity with floating environment promotes migration of non-small cell lung cancers. Sci. Rep. 9:14553. doi: 10.1038/s41598-01950736-6

Aleshcheva, G., Sahana, J., Ma, X., Hauslage, J., Hemmersbach, R., Egli, M., et al. (2013). Changes in morphology, gene expression and protein content in chondrocytes cultured on a random positioning machine. PLoS One 8:e79057. doi: 10.1371/journal.pone.0079057

Aleshcheva, G., Wehland, M., Sahana, J., Bauer, J., Corydon, T. J., Hemmersbach, R., et al. (2015). Moderate alterations of the cytoskeleton in human chondrocytes after short-term microgravity produced by parabolic flight maneuvers could be prevented by up-regulation of BMP-2 and SOX-9. FASEB J. 29, 2303-2314. doi: 10.1096/fj.14-268151

Bavi, N., Richardson, J., Heu, C., Martinac, B., and Poole, K. (2019). PIEZO1mediated currents are modulated by substrate mechanics. ACS Nano 13, 13545-13559. doi: 10.1021/acsnano.9b07499

Beysens, D. A., and van Loon, J. J. W. A. (2015). Generation and Applications of Extra-Terrestrial Environments on Earth. Denmark: River Publishers.

Boonyaratanakornkit, J. B., Cogoli, A., Li, C. F., Schopper, T., Pippia, P., Galleri, G., et al. (2005). Key gravity-sensitive signaling pathways drive T cell activation. FASEB J. 19, 2020-2022. doi: 10.1096/fj.05-3778fje

Bradley, J. H., Barwick, S., Horn, G. Q., Ullrich, E., Best, B., Arnold, J. P., et al. (2019). Simulated microgravity-mediated reversion of murine lymphoma immune evasion. Sci. Rep. 9:14623. doi: 10.1038/s41598-019-51106-y

Buken, C., Sahana, J., Corydon, T. J., Melnik, D., Bauer, J., Wehland, M., et al. (2019). Morphological and molecular changes in juvenile normal human fibroblasts exposed to simulated microgravity. Sci. Rep. 9:11882. doi: 10.1038/ s41598-019-48378-9

Burger, E. H., and Klein-Nulend, J. (1998). Microgravity and bone cell mechanosensitivity. Bone 22 (5 Suppl.), 127S-130S. doi: 10.1016/s87563282(98)00010-6

Carlsson, S. I., Bertilaccio, M. T., Ballabio, E., and Maier, J. A. (2003). Endothelial stress by gravitational unloading: effects on cell growth and cytoskeletal organization. Biochim. Biophys. Acta 1642, 173-179. doi: 10.1016/j.bbamcr. 2003.08.003

Corydon, T. J., Kopp, S., Wehland, M., Braun, M., Schutte, A., Mayer, T., et al. (2016a). Alterations of the cytoskeleton in human cells in space proved by life-cell imaging. Sci. Rep. 6:20043. doi: 10.1038/srep20043

Corydon, T. J., Mann, V., Slumstrup, L., Kopp, S., Sahana, J., Askou, A. L., et al. (2016b). Reduced expression of cytoskeletal and extracellular matrix genes in human adult retinal pigment epithelium cells exposed to simulated microgravity. Cell. Physiol. Biochem. 40, 1-17. doi: 10.1159/00045 2520

Crawford-Young, S. J. (2006). Effects of microgravity on cell cytoskeleton and embryogenesis. Int. J. Dev. Biol. 50, 183-191. doi: 10.1387/ijdb.052077sc

Crucian, B., Simpson, R. J., Mehta, S., Stowe, R., Chouker, A., Hwang, S. A., et al. (2014). Terrestrial stress analogs for spaceflight associated immune system dysregulation. Brain Behav. Immun. 39, 23-32. doi: 10.1016/j.bbi.2014.01.011

Crucian, B., Stowe, R., Quiriarte, H., Pierson, D., and Sams, C. (2011). Monocyte phenotype and cytokine production profiles are dysregulated by short-duration spaceflight. Aviat. Space Environ. Med. 82, 857-862. doi: 10.3357/asem.3047. 2011

Crucian, B., Stowe, R. P., Mehta, S., Quiriarte, H., Pierson, D., and Sams, C. (2015). Alterations in adaptive immunity persist during long-duration spaceflight. NPJ Microgravity 1:15013. doi: 10.1038/npjmgrav.2015.13

Dietz, C., Infanger, M., Romswinkel, A., Strube, F., and Kraus, A. (2019). Apoptosis induction and alteration of cell adherence in human lung cancer cells under simulated microgravity. Int. J. Mol. Sci. 20:E3601. doi: 10.3390/ijms201 43601

Ellefsen, K. L., Holt, J. R., Chang, A. C., Nourse, J. L., Arulmoli, J., Mekhdjian, A. H., et al. (2019). Myosin-II mediated traction forces evoke localized Piezo1dependent $\mathrm{Ca}(2+)$ flickers. Commun. Biol. 2:298.

Fitts, R. H., Riley, D. R., and Widrick, J. J. (2001). Functional and structural adaptations of skeletal muscle to microgravity. J. Exp. Biol. 204(Pt 18), 32013208 .
Fitzgerald, J., Endicott, J., Hansen, U., and Janowitz, C. (2019). Articular cartilage and sternal fibrocartilage respond differently to extended microgravity. NPJ Microgravity 5:3. doi: 10.1038/s41526-019-0063-6

Frippiat, J. P., Crucian, B. E., de Quervain, D. J., Grimm, D., Montano, N., Praun, S., et al. (2016). Towards human exploration of space: the THESEUS review series on immunology research priorities. NPJ Microgravity 2:16040. doi: 10 . 1038/npjmgrav.2016.40

Grenon, S. M., Jeanne, M., Aguado-Zuniga, J., Conte, M. S., and Hughes-Fulford, M. (2013). Effects of gravitational mechanical unloading in endothelial cells: association between caveolins, inflammation and adhesion molecules. Sci. Rep. 3:1494. doi: 10.1038/srep01494

Grimm, D., Bauer, J., Kossmehl, P., Shakibaei, M., Schoberger, J., Pickenhahn, H., et al. (2002). Simulated microgravity alters differentiation and increases apoptosis in human follicular thyroid carcinoma cells. FASEB J. 16, 604-606. doi: 10.1096/fj.01-0673fje

Gruener, R., Roberts, R., Fau-Reitstetter, R., and Reitstetter, R. (1994). Reduced receptor aggregation and altered cytoskeleton in cultured myocytes after spaceflight. Biol. Sci. Space 8, 79-93. doi: 10.2187/bss.8.79

Guignandon, A., Akhouayri, O., Usson, Y., Rattner, A., Laroche, N., LafageProust, M. H., et al. (2003). Focal contact clustering in osteoblastic cells under mechanical stresses: microgravity and cyclic deformation. Cell Commun. Adhes. 10, 69-83. doi: 10.1080/15419060390260987

Guignandon, A., Genty, C., Vico, L., Lafage-Proust, M. H., Palle, S., and Alexandre, C. (1997). Demonstration of feasibility of automated osteoblastic line culture in space flight. Bone 20, 109-116. doi: 10.1016/s8756-3282(96)00337-7

Guignandon, A., Vico, L., Alexandre, C., and Lafage-Proust, M. H. (1995). Shape changes of osteoblastic cells under gravitational variations during parabolic flight-relationship with PGE2 synthesis. Cell Struct. Funct. 20, 369-375. doi: 10.1247/csf.20.369

Haapala, J., Lammi, M. J., Inkinen, R., Parkkinen, J. J., Agren, U. M., Arokoski, J., et al. (1996). Coordinated regulation of hyaluronan and aggrecan content in the articular cartilage of immobilized and exercised dogs. J. Rheumatol. 23, 1586-1593.

Harris, S. A., Zhang, M., Kidder, L. S., Evans, G. L., Spelsberg, T. C., and Turner, R. T. (2000). Effects of orbital spaceflight on human osteoblastic cell physiology and gene expression. Bone 26, 325-331. doi: 10.1016/s8756-3282(00)00234-9

Herranz, R., Anken, R., Boonstra, J., Braun, M., Christianen, P. C., de Geest, M., et al. (2013). Ground-based facilities for simulation of microgravity: organismspecific recommendations for their use, and recommended terminology. Astrobiology 13, 1-17. doi: 10.1089/ast.2012.0876

Herranz, R., Larkin, O. J., Dijkstra, C. E., Hill, R. J., Anthony, P., Davey, M. R., et al. (2012). Microgravity simulation by diamagnetic levitation: effects of a strong gradient magnetic field on the transcriptional profile of Drosophila melanogaster. BMC Genomics 13:52. doi: 10.1186/1471-2164-13-52

Higashibata, A., Imamizo-Sato, M., Seki, M., Yamazaki, T., and Ishioka, N. (2006). Influence of simulated microgravity on the activation of the small GTPase Rho involved in cytoskeletal formation-molecular cloning and sequencing of bovine leukemia-associated guanine nucleotide exchange factor. BMC Biochem. 7:19. doi: 10.1186/1471-2091-7-19

Horneck, G., Facius, R., Reichert, M., Rettberg, P., Seboldt, W., Manzey, D., et al. (2003). HUMEX, a study on the survivability and adaptation of humans to long-duration exploratory missions, part I: lunar missions. Adv. Space Res. 31, 2389-2401. doi: 10.1016/s0273-1177(03)00568-4

Hughes-Fulford, M. (2003). Function of the cytoskeleton in gravisensing during spaceflight. Adv. Space Res. 32, 1585-1593. doi: 10.1016/s0273-1177(03) 90399-1

Hughes-Fulford, M., and Lewis, M. L. (1996). Effects of microgravity on osteoblast growth activation. Exp. Cell Res. 224, 103-109.

Huijser, R. (2000). Desktop RPM: New Small Size Microgravity Simulator for the Bioscience Laboratory. Amsterdam: Fokker Space.

Ikeda, H., Souda, H., Puspitasari, A., Held, K. D., Hidema, J., Nikawa, T., et al. (2017). Development and performance evaluation of a three-dimensional clinostat synchronized heavy-ion irradiation system. Life Sci. Space Res. 12, 51-60. doi: 10.1016/j.lssr.2017.01.003

Infanger, M., Kossmehl, P., Shakibaei, M., Baatout, S., Witzing, A., Grosse, J., et al. (2006a). Induction of three-dimensional assembly and increase in apoptosis of human endothelial cells by simulated microgravity: impact of vascular 
endothelial growth factor. Apoptosis 11, 749-764. doi: 10.1007/s10495-0065697-7

Infanger, M., Kossmehl, P., Shakibaei, M., Bauer, J., Kossmehl-Zorn, S., Cogoli, A., et al. (2006b). Simulated weightlessness changes the cytoskeleton and extracellular matrix proteins in papillary thyroid carcinoma cells. Cell Tissue Res. 324, 267-277. doi: 10.1007/s00441-005-0142-8

Ingber, D. (1999). How cells (might) sense microgravity. FASEB J. 13(Suppl.), S3-S15. doi: 10.1096/fasebj.13.9001.s3

Ingber, D. E. (1997). Tensegrity: the architectural basis of cellular mechanotransduction. Annu. Rev. Physiol. 59, 575-599. doi: 10.1146/annurev. physiol.59.1.575

Janmaleki, M., Pachenari, M., Seyedpour, S. M., Shahghadami, R., and SanatiNezhad, A. (2016). Impact of simulated microgravity on cytoskeleton and viscoelastic properties of endothelial cell. Sci. Rep. 6:32418. doi: 10.1038/ srep32418

Jeong, A. J., Kim, Y. J., Lim, M. H., Lee, H., Noh, K., Kim, B.-H., et al. (2018). Microgravity induces autophagy via mitochondrial dysfunction in human Hodgkin's lymphoma cells. Sci. Rep. 8:14646. doi: 10.1038/s41598-018-32965-3

Kamiya, N., Shuxian, L., Yamaguchi, R., Phipps, M., Aruwajoye, O., Adapala, N. S., et al. (2016). Targeted disruption of BMP signaling through type IA receptor (BMPR1A) in osteocyte suppresses SOST and RANKL, leading to dramatic increase in bone mass, bone mineral density and mechanical strength. Bone 91, 53-63. doi: 10.1016/j.bone.2016.07.002

Kopp, S., Krüger, M., Feldmann, S., Oltmann, H., Schütte, A., Schmitz, B., et al. (2018a). Thyroid cancer cells in space during the TEXUS-53 sounding rocket mission - the THYROID project. Sci. Rep. 8:10355. doi: 10.1038/s41598-01828695- 1

Kopp, S., Sahana, J., Islam, T., Petersen, A. G., Bauer, J., Corydon, T. J., et al. (2018b). The role of NFKB in spheroid formation of human breast cancer cells cultured on the Random Positioning Machine. Sci. Rep. 8:921. doi: 10.1038/ s41598-017-18556-8

Kopp, S., Warnke, E., Wehland, M., Aleshcheva, G., Magnusson, N. E., Hemmersbach, R., et al. (2015). Mechanisms of three-dimensional growth of thyroid cells during long-term simulated microgravity. Sci. Rep. 5:16691. doi: 10.1038/srep16691

Krüger, M., Melnik, D., Kopp, S., Buken, C., Sahana, J., Bauer, J., et al. (2019a). Fighting thyroid cancer with microgravity research. Int. J. Mol. Sci. 20:2553. doi: 10.3390/ijms20102553

Krüger, M., Pietsch, J., Bauer, J., Kopp, S., Carvalho, D. T. O., Baatout, S., et al. (2019b). Growth of endothelial cells in space and in simulated microgravity - a comparison on the secretory level. Cell Physiol. Biochem. 52, 1039-1060. doi: 10.33594/000000071

Kurz, B., Lemke, A. K., Fay, J., Pufe, T., Grodzinsky, A. J., and Schunke, M. (2005). Pathomechanisms of cartilage destruction by mechanical injury. Ann. Anat. 187, 473-485. doi: 10.1016/j.aanat.2005.07.003

Lewis, M. L., Reynolds, J. L., Cubano, L. A., Hatton, J. P., Lawless, B. D., and Piepmeier, E. H. (1998). Spaceflight alters microtubules and increases apoptosis in human lymphocytes (Jurkat). FASEB J. 12, 1007-1018. doi: 10.1096/fasebj.12. 11.1007

Li, J., Zhang, S., Chen, J., Du, T., Wang, Y., and Wang, Z. (2009). Modeled microgravity causes changes in the cytoskeleton and focal adhesions, and decreases in migration in malignant human MCF-7 cells. Protoplasma 238, 23-33. doi: 10.1007/s00709-009-0068-1

Louis, F., Bouleftour, W., Rattner, A., Linossier, M. T., Vico, L., and Guignandon, A. (2017). RhoGTPase stimulation is associated with strontium chloride treatment to counter simulated microgravity-induced changes in multipotent cell commitment. NPJ Microgravity 3:7. doi: 10.1038/s41526-0160004-6

Maniotis, A. J., Chen, C. S., and Ingber, D. E. (1997). Demonstration of mechanical connections between integrins, cytoskeletal filaments, and nucleoplasm that stabilize nuclear structure. Proc. Natl. Acad. Sci. U.S.A. 94, 849-854. doi: 10. 1073/pnas.94.3.849

Mann, V., Grimm, D., Corydon, T. J., Kruger, M., Wehland, M., Riwaldt, S., et al. (2019). Changes in human foetal osteoblasts exposed to the random positioning machine and bone construct tissue engineering. Int. J. Mol. Sci. 20:1357. doi: 10.3390/ijms20061357

Martin, M., Sansalone, V., Cooper, D. M. L., Forwood, M. R., and Pivonka, P. (2020). Assessment of romosozumab efficacy in the treatment of postmenopausal osteoporosis: results from a mechanistic PK-PD mechanostat model of bone remodeling. Bone doi: 10.1016/j.bone.2020.115223 [Epub ahead of print].

Martinez, E. M., Yoshida, M. C., Candelario, T. L., and Hughes-Fulford, M. (2015). Spaceflight and simulated microgravity cause a significant reduction of key gene expression in early T-cell activation. Am. J. Physiol. Regul. Integr. Comp. Physiol. 308, R480-R488. doi: 10.1152/ajpregu.004 49.2014

Nabavi, N., Khandani, A., Camirand, A., and Harrison, R. E. (2011). Effects of microgravity on osteoclast bone resorption and osteoblast cytoskeletal organization and adhesion. Bone 49, 965-974. doi: 10.1016/j.bone.2011.07.036

Nassef, M. Z., Kopp, S., Wehland, M., Melnik, D., Sahana, J., Kruger, M., et al. (2019). Real microgravity influences the cytoskeleton and focal adhesions in human breast cancer cells. Int. J. Mol. Sci. 20:3156. doi: 10.3390/ijms20133156

Nourse, J. L., and Pathak, M. M. (2017). How cells channel their stress: interplay between Piezol and the cytoskeleton. Semin. Cell Dev. Biol. 71, 3-12. doi: 10.1016/j.semcdb.2017.06.018

O'Connor, K. M. (1997). Unweighting accelerates tidemark advancement in articular cartilage at the knee joint of rats. J. Bone Miner. Res. 12, 580-589. doi: 10.1359/jbmr.1997.12.4.580

Okumura, S., Mizoguchi, T., Sato, N., Yamaki, M., Kobayashi, Y., Yamauchi, H., et al. (2006). Coordination of microtubules and the actin cytoskeleton is important in osteoclast function, but calcitonin disrupts sealing zones without affecting microtubule networks. Bone 39, 684-693. doi: 10.1016/j.bone.2006.04. 010

Pajevic, P. D., Spatz, J. M., Garr, J., Adamson, C., and Misener, L. (2013). Osteocyte biology and space flight. Curr. Biotechnol. 2, 179-183. doi: 10.2174/ 22115501113029990017

Papaseit, C., Pochon, N., and Tabony, J. (2000). Microtubule self-organization is gravity-dependent. Proc. Natl. Acad. Sci. U.S.A. 97, 8364-8368. doi: 10.1073/ pnas. 140029597

Patel, M. J., Liu, W., Sykes, M. C., Ward, N. E., Risin, S. A., Risin, D., et al. (2007). Identification of mechanosensitive genes in osteoblasts by comparative microarray studies using the rotating wall vessel and the random positioning machine. J. Cell Biochem. 101, 587-599. doi: 10.1002/jcb. 21218

Pavlakou, P., Dounousi, E., Roumeliotis, S., Eleftheriadis, T., and Liakopoulos, V. (2018). Oxidative stress and the kidney in the space environment. Int. J. Mol. Sci. 19:3176. doi: 10.3390/ijms19103176

Plett, P. A., Abonour, R., Frankovitz, S. M., and Orschell, C. M. (2004). Impact of modeled microgravity on migration, differentiation, and cell cycle control of primitive human hematopoietic progenitor cells. Exp. Hematol. 32, 773-781. doi: 10.1016/j.exphem.2004.03.014

Poole, K. E., van Bezooijen, R. L., Loveridge, N., Hamersma, H., Papapoulos, S. E., Lowik, C. W., et al. (2005). Sclerostin is a delayed secreted product of osteocytes that inhibits bone formation. FASEB J. 19, 1842-1844. doi: 10.1096/ fj.05-4221fje

Ratushnyy, A. Y., and Buravkova, L. B. (2017). Expression of focal adhesion genes in mesenchymal stem cells under simulated microgravity. Dokl. Biochem. Biophys. 477, 354-356. doi: 10.1134/s1607672917060035

Rijken, P. J., de Groot, R. P., Briegleb, W., Kruijer, W., Verkleij, A. J., Boonstra, J., et al. (1991). Epidermal growth factor-induced cell rounding is sensitive to simulated microgravity. Aviat. Space Environ. Med. 62, 32-36.

Rijken, P. J., de Groot, R. P., Kruijer, W., de Laat, S. W., Verkleij, A. J., and Boonstra, J. (1992). Identification of specific gravity sensitive signal transduction pathways in human A431 carcinoma cells. Adv. Space Res. 12, 145-152. doi: 10.1016/ 0273-1177(92)90277-5

Robling, A. G., Niziolek, P. J., Baldridge, L. A., Condon, K. W., Allen, M. R., Alam, I., et al. (2008). Mechanical stimulation of bone in vivo reduces osteocyte expression of Sost/sclerostin. J. Biol. Chem. 283, 5866-5875. doi: 10.1074/jbc. M705092200

Rodionova, N. V., Oganov, V. S., and Zolotova, N. V. (2002). Ultrastructural changes in osteocytes in microgravity conditions. Adv. Space Res. 30, 765-770. doi: 10.1016/s0273-1177(02)00393-9

Rosner, H., Wassermann, T., Moller, W., and Hanke, W. (2006). Effects of altered gravity on the actin and microtubule cytoskeleton of human $\mathrm{SH}$ SY5Y neuroblastoma cells. Protoplasma 229, 225-234. doi: 10.1007/s00709006-0202-2

Russomano, T., Cardoso, R., Falcao, F., Dalmarco, G., Santos, C. V. D., Santos, L. F. D., et al. (2005). Development and validation of a 3D clinostat for the study 
of cells during microgravity simulation. Conf. Proc. IEEE Eng. Med. Biol. Soc. 1, 564-566. doi: 10.1109/iembs.2005.1616474

Salter, R. B., Simmonds, D. F., Malcolm, B. W., Rumble, E. J., MacMichael, D., and Clements, N. D. (1980). The biological effect of continuous passive motion on the healing of full-thickness defects in articular cartilage. An experimental investigation in the rabbit. J. Bone Joint Surg. Am. 62, 1232-1251. doi: 10.2106/ 00004623-198062080-00002

Sanchez-Adams, J., Leddy, H. A., McNulty, A. L., O'Conor, C. J., and Guilak, F. (2014). The mechanobiology of articular cartilage: bearing the burden of osteoarthritis. Curr. Rheumatol. Rep. 16:451. doi: 10.1007/s11926-014-0451-6

Scheiber, A. L., Barton, D. K., Khoury, B. M., Marini, J. C., Swiderski, D. L., Caird, M. S., et al. (2019). Sclerostin antibody-induced changes in bone mass are site specific in developing Crania. J. Bone Miner. Res. 34, 2301-2310. doi: $10.1002 / j b m r .3858$

Sciola, L., Cogoli-Greuter, M., Cogoli, A., Spano, A., and Pippia, P. (1999). Influence of microgravity on mitogen binding and cytoskeleton in Jurkat cells. Adv. Space Res. 24, 801-805. doi: 10.1016/s0273-1177(99)00078-2

Shi, Z. X., Rao, W., Wang, H., Wang, N. D., Si, J. W., Zhao, J., et al. (2015). Modeled microgravity suppressed invasion and migration of human glioblastoma U87 cells through downregulating store-operated calcium entry. Biochem. Biophys. Res. Commun. 457, 378-384. doi: 10.1016/j.bbrc.2014.12.120

Smith, J. K. (2018). IL-6 and the dysregulation of immune, bone, muscle, and metabolic homeostasis during spaceflight. NPJ Microgravity 4:24. doi: 10.1038/ s41526-018-0057-9

Sonnenfeld, G., Mandel, A. D., Konstantinova, I. V., Berry, W. D., Taylor, G. R., Lesnyak, A. T., et al. (1992). Spaceflight alters immune cell function and distribution. J. Appl. Physiol. 73(2 Suppl.), 191S-195S. doi: 10.1152/jappl.1992. 73.2.S191

Stamenkovic, V., Keller, G., Nesic, D., Cogoli, A., and Grogan, S. P. (2010). Neocartilage formation in $1 \mathrm{~g}$, simulated, and microgravity environments: implications for tissue engineering. Tissue Eng. Part A 16, 1729-1736. doi: $10.1089 /$ ten.tea.2008.0624

Tabony, J., Glade, N., Papaseit, C., and Demongeot, J. (2002). Microtubule selforganisation and its gravity dependence. Adv. Space Biol. Med. 8, 19-58. doi: 10.1016/s1569-2574(02)08014-0

Tan, X., Xu, A., Zhao, T., Zhao, Q., Zhang, J., Fan, C., et al. (2018). Simulated microgravity inhibits cell focal adhesions leading to reduced melanoma cell proliferation and metastasis via FAK/RhoA-regulated mTORC1 and AMPK pathways. Sci. Rep. 8:3769. doi: 10.1038/s41598-018-2 0459-1

Tauber, S., Lauber, B. A., Paulsen, K., Layer, L. E., Lehmann, M., Hauschild, S., et al. (2017). Cytoskeletal stability and metabolic alterations in primary human macrophages in long-term microgravity. PLoS One 12:e0175599. doi: 10.1371/ journal.pone. 0175599

Thiel, C. S., Hauschild, S., Huge, A., Tauber, S., Lauber, B. A., Polzer, J., et al. (2017). Dynamic gene expression response to altered gravity in human T cells. Sci. Rep. 7:5204. doi: 10.1038/s41598-017-05580-x

Thiel, C. S., Tauber, S., Lauber, B., Polzer, J., Seebacher, C., Uhl, R., et al. (2019a). Rapid morphological and cytoskeletal response to microgravity in human primary macrophages. Int. J. Mol. Sci. 20:2402. doi: 10.3390/ijms20102402

Thiel, C. S., Tauber, S., Seebacher, C., Schropp, M., Uhl, R., Lauber, B., et al. (2019b). Real-time 3D high-resolution microscopy of human cells on the international space station. Int. J. Mol. Sci. 20:2033. doi: 10.3390/ijms20082033

Ulbrich, C., Westphal, K., Pietsch, J., Winkler, H. D., Leder, A., Bauer, J., et al. (2010). Characterization of human chondrocytes exposed to simulated microgravity. Cell Physiol. Biochem. 25, 551-560. doi: 10.1159/000303059

Ulbrich, C., Pietsch, J., Grosse, J., Wehland, M., Schulz, H., Saar, K., et al. (2011). Differential gene regulation under altered gravity conditions in follicular thyroid cancer cells: relationship between the extracellular matrix and the cytoskeleton. Cell. Physiol. Biochem. 28, 185-198. doi: 10.1159/000331730

Uva, B. M., Masini, M. A., Sturla, M., Prato, P., Passalacqua, M., Giuliani, M., et al. (2002). Clinorotation-induced weightlessness influences the cytoskeleton of glial cells in culture. Brain Res. 934, 132-139. doi: 10.1016/s0006-8993(02) 02415-0

Vanwanseele, B., Eckstein, F., Knecht, H., Stussi, E., and Spaepen, A. (2002). Knee cartilage of spinal cord-injured patients displays progressive thinning in the absence of normal joint loading and movement. Arthritis Rheum. 46, 2073-2078. doi: 10.1002/art.10462

Vassy, J., Portet, S., Beil, M., Millot, G., Fauvel-Lafeve, F., Karniguian, A., et al. (2001). The effect of weightlessness on cytoskeleton architecture and proliferation of human breast cancer cell line MCF-7. FASEB J. 15, 1104-1106. doi: 10.1096/fj.00-0527fje

Vassy, J., Portet, S., Beil, M., Millot, G., Fauvel-Laféve, F., Gasset, G., et al. (2003). Weightlessness acts on human breast cancer cell line MCF-7. Adv. Space Res. 32, 1595-1603. doi: 10.1016/S0273-1177(03)90400-5

Vidyasekar, P., Shyamsunder, P., Arun, R., Santhakumar, R., Kapadia, N. K., Kumar, R., et al. (2015). Genome wide expression profiling of cancer cell lines cultured in microgravity reveals significant dysregulation of cell cycle and MicroRNA gene networks. PLoS One 10:e0135958. doi: 10.1371/journal.pone.0135958

Vorselen, D., Roos, W. H., MacKintosh, F. C., Wuite, G. J., and van Loon, J. J. (2014). The role of the cytoskeleton in sensing changes in gravity by nonspecialized cells. FASEB J. 28, 536-547. doi: 10.1096/fj.13-236356

Wang, N., Butler, J. P., and Ingber, D. E. (1993). Mechanotransduction across the cell surface and through the cytoskeleton. Science 260, 1124-1127. doi: $10.1126 /$ science. 7684161

White, O., Clement, G., Fortrat, J. O., Pavy-LeTraon, A., Thonnard, J. L., Blanc, S., et al. (2016). Towards human exploration of space: the THESEUS review series on neurophysiology research priorities. NPJ Microgravity 2:16023. doi: 10.1038/npjmgrav.2016.23

White, R. J., and Averner, M. (2001). Humans in space. Nature 409, 1115-1118. doi: $10.1038 / 35059243$

Wolfenson, H., Bershadsky, A., Henis, Y. I., and Geiger, B. (2011). Actomyosingenerated tension controls the molecular kinetics of focal adhesions. J. Cell Sci. 124(Pt 9), 1425-1432. doi: $10.1242 /$ jcs.077388

Wolfenson, H., Lubelski, A., Regev, T., Klafter, J., Henis, Y. I., and Geiger, B. (2009). A role for the juxtamembrane cytoplasm in the molecular dynamics of focal adhesions. PLoS One 4:e4304. doi: 10.1371/journal.pone.0004304

Xu, H., Wu, F., Zhang, H., Yang, C., Li, K., Wang, H., et al. (2017). Actin cytoskeleton mediates BMP2-Smad signaling via calponin 1 in preosteoblast under simulated microgravity. Biochimie 138, 184-193. doi: 10.1016/j.biochi. 2017.04.015

Zaidel-Bar, R., Ballestrem, C., Kam, Z., and Geiger, B. (2003). Early molecular events in the assembly of matrix adhesions at the leading edge of migrating cells. J. Cell Sci. 116(Pt 22), 4605-4613. doi: 10.1242/jcs.00792

Conflict of Interest: The authors declare that the research was conducted in the absence of any commercial or financial relationships that could be construed as a potential conflict of interest.

Copyright $\odot 2020$ Bradbury, Wu, Choi, Rowan, Zhang, Poole, Lauko and Chou. This is an open-access article distributed under the terms of the Creative Commons Attribution License (CC BY). The use, distribution or reproduction in other forums is permitted, provided the original author(s) and the copyright owner(s) are credited and that the original publication in this journal is cited, in accordance with accepted academic practice. No use, distribution or reproduction is permitted which does not comply with these terms. 